\title{
Increased production of alkaline polygalacturonate lyase in the recombinant WB43CB by optimizing the medium
}

\author{
Junjiao Zhang ${ }^{1, *}$, Junli Zhang ${ }^{2, *}$ \\ ${ }^{1}$ Qilu institute of technology, 250200 Jinan, China \\ ${ }^{2}$ School of Life Sciences, Shandong First Medical University \& Shandong Academy of Medical Sciences, 271000 Taian, China
}

\begin{abstract}
Alkaline polygalacturonate lyase (PGL), which was the central enzyme of green environmental enzyme treatment technology, has been widely used in textile, papermaking and beverage production. In the previous work, Bacillus subtilis was used as the expression host, and the PGL gene derived from $B$. subtilisWSHB04-02 was successfully expressed in the engineered strain WB43CB by regulating of molecular elements such as signal peptide, promoter and SD sequence. In this study, the fermentation medium was optimized from four aspects of carbon source, nitrogen source, liquid volume and inoculum volume, and the extracellular PGL enzyme activity in WB43CB increased from $264.5 \mathrm{U} \cdot \mathrm{mL}^{-1}$ to 461.96 $\mathrm{U} \cdot \mathrm{mL}^{-1}$, which laid a solid foundation for the industrial production of PGL.
\end{abstract}

\section{Introduction}

In recent years, due to the importance of environmental issues and the pressure from the public, many countries have enacted environmental legislation, forcing industrial producers to seek environmentally friendly processes to replace traditional chemical processes. The environmental pollution problems in the textile production process have increasingly attracted social attention ${ }^{[1]}$. Along with the rapid development of genetic engineering and protein engineering, biological enzyme preparations have used in many industrial productions replacing traditional chemicals. Among the many enzyme products used in the textile industry, alkaline pectinase with strong alkali resistance, high temperature resistance, and a wide range of sources, has been widely used in the textile industry, paper industry and food industry ${ }^{[2]}$. In recent years, research mainly focus on selection and construction of wild strains producing alkaline pectinase. B. subtilis is considered to be the most suitable strain for PGL production by the features of strong protein secretion system, good safety performance, no obvious codon preference, clear genetic background research and simple fermentation conditions ${ }^{[3-5]}$.

In the previous work, B. subtilis was used as the expression host and the PGL gene derived from $B$. subtilisWSHB04-02 was successfully expressed in the engineered strain WB43CB by regulating of molecular elements such as signal peptide, promoter, and SD sequence, but the yield is still low. In this study, the fermentation medium for PGL production by recombinant strain WB43CB was optimized from four aspects of carbon source, nitrogen source, liquid volume, and inoculum volume. The PGL production of WB43CB was further improved and the optimized seed culture medium and fermentation culture medium was confirmed, which laid a solid foundation for the PGL industrial production.

\section{Materials and methods}

\subsection{Strains}

B. subtilisWSHB04-02 was screened by our laboratory, and WB43CB was constructed by this research.

\subsection{Medium}

LB medium $\left(\mathrm{g} \cdot \mathrm{L}^{-1}\right)$ : peptone 10 , yeast powder $5, \mathrm{NaCl} 10$, $\mathrm{pH}$ 7.0.

Seed medium $\left(\mathrm{g} \cdot \mathrm{L}^{-1}\right)$ : sucrose 20 , corn steep liquor 30 , peptone 10, $\mathrm{KH}_{2} \mathrm{PO}_{4} 6, \mathrm{~K}_{2} \mathrm{HPO}_{4}$ 18.4, $\mathrm{pH}$ 7.0.

Fermentation medium $\left(\mathrm{g} \cdot \mathrm{L}^{-1}\right)$ : corn starch 15 , peptone 8, yeast powder $10, \mathrm{KH}_{2} \mathrm{PO}_{4} 3, \mathrm{~K}_{2} \mathrm{HPO}_{4}$ 9.2, $\mathrm{pH}$ 7.0.

\subsection{Analytical method}

The activity of alkaline PGL was determined by measuring the absorbance of unsaturated bonds between $\mathrm{C}_{4}$ and $\mathrm{C}_{5}$ of galacturonic acid at $235 \mathrm{~nm}$. The reaction mixture contained $2 \mathrm{~mL}$ of $0.2 \%(\mathrm{w} / \mathrm{v})$ polygalacturonic acid in $200 \mathrm{mM}$ glycine- $\mathrm{NaOH}$ buffer at $\mathrm{pH} 9.4$ (containing $200 \mathrm{mM}$ glycine, $200 \mathrm{mM} \mathrm{NaOH}$, and 60 
$\mathrm{mM} \mathrm{CaCl}_{2}$ ) and $20 \mu \mathrm{L}$ of diluted enzyme solution. The reaction mixture was incubated at $45{ }^{\circ} \mathrm{C}$ for $15 \mathrm{~min}$, and then the reaction was terminated by adding $3 \mathrm{~mL}$ of 30 $\mathrm{mM}$ phosphoric acid. The product was analyzed by a spectrophotometer. One enzyme unit was defined as formation of $1 \mu \mathrm{moL}$ unsaturated polygalacturonic acid per minute, with a molar extinction coefficient of 4600 $\mathrm{M}^{-1} \mathrm{~cm}^{-1}$ at $235 \mathrm{~nm}$.

\section{Results and discussion}

\subsection{The effect of carbon source on the growth and enzyme production of WB43CB}

Taking $15 \mathrm{~g} \cdot \mathrm{L}^{-1}$ of corn starch as the standard, the glucose, corn starch, sucrose, soluble starch and $\alpha$-lactose with same carbon content were added to me- dium. The fermentation results were shown in fig. 1 .

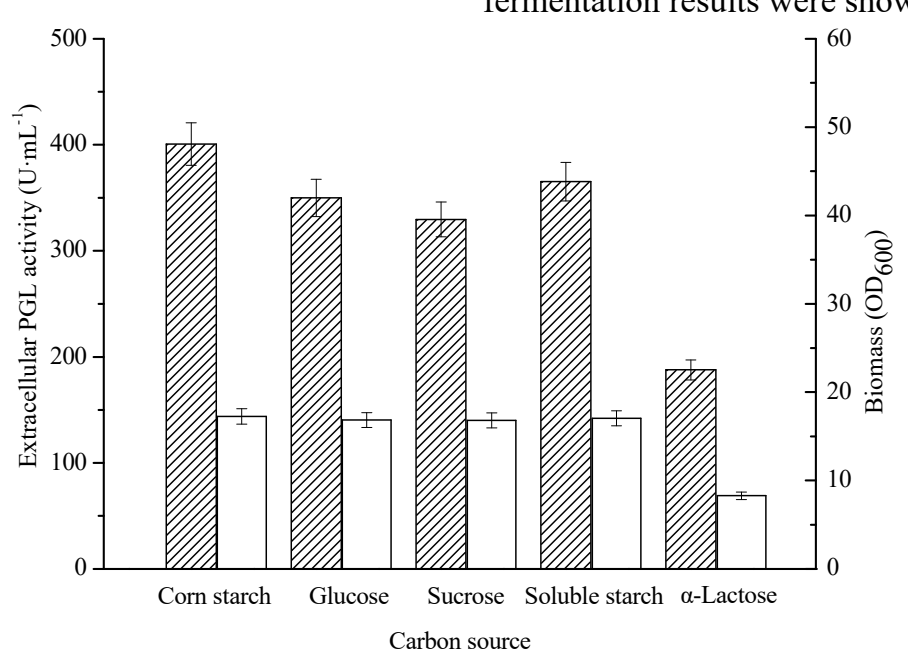

Fig. 1 Effect of different carbon source on cell growth and PGL production Extracellular PGL activity (slash), Biomass (white).

When glucose, corn starch, sucrose, soluble starch and $\alpha$-lactose were used as carbon sources for fermentation, the biomass $\left(\mathrm{OD}_{600}\right)$ were $16.85,17.25$, 16.80, 17.05 and 8.28, respectively, and the extracellular PGL activities were $\left(\mathrm{U} \cdot \mathrm{mL}^{-1}\right)$ : 350.00, 400.73, 329.71, 365.22 and 187.68. When corn starch was used as a carbon source for fermentation, the extracellular enzyme activity was the highest. The corn starch was hydrolyzed in the medium to generate monosaccharides and dextrins, which could meet the requirements of bacteria and not inhibit the enzyme production. Therefore, corn starch was choosen as the carbon source of fermentation medium.

On this basis, the optimum corn starch concentration was explored. As shown in fig. 2, when the added amount of corn starch were $\left(\mathrm{g} \cdot \mathrm{L}^{-1}\right): 10,15,25,35$ and 45 , the bacterial cell concentration were $14.55,17.25,19.35$, 19.65 and 19.75 respectively. Correspondingly, the extracellular enzyme activities were $\left(\mathrm{U} \cdot \mathrm{mL}^{-1}\right): 333.33$, $413.77,464.68,473.73$, and 483.70. When the corn starch concentration increased from $10 \mathrm{~g} \cdot \mathrm{L}^{-1}$ to $15 \mathrm{~g} \cdot \mathrm{L}^{-1}$ and from $15 \mathrm{~g} \cdot \mathrm{L}^{-1}$ to $25 \mathrm{~g} \cdot \mathrm{L}^{-1}$, the maximum extracellular enzyme activity increased by $24.1 \%$ and $12.3 \%$, when the corn starch concentration increased from $25 \mathrm{~g} \cdot \mathrm{L}^{-1}$ to $35 \mathrm{~g} \cdot \mathrm{L}^{-1}$ and from $35 \mathrm{~g} \cdot \mathrm{L}^{-1}$ to $45 \mathrm{~g} \cdot \mathrm{L}^{-1}$, the increase in extracellular enzyme activity was less than $3.00 \%$, the increase in enzyme activity is not obvious. Considering the cost of raw materials, the amount of corn starch added is $25 \mathrm{~g} \cdot \mathrm{L}^{-1}$.

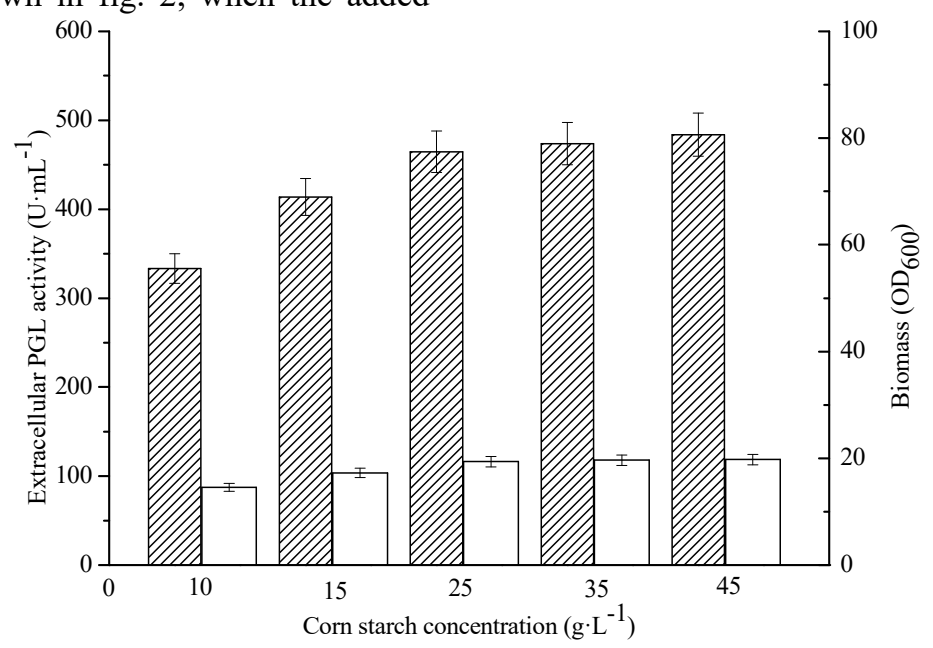

Fig. 2 Effect of different corn starch concentration on cell growth and PGL production Extracellular PGL activity (slash), Biomass (white) 


\subsection{The effect of nitrogen source on the growth and enzyme production of WB43CB}

In this study, organic nitrogen source corn steep liquor, yeast extract, angel yeast, beef extract and inorganic nitrogen source $\left(\mathrm{NH}_{4}\right)_{2} \mathrm{SO}_{4}$ were added to the medium and fermented.

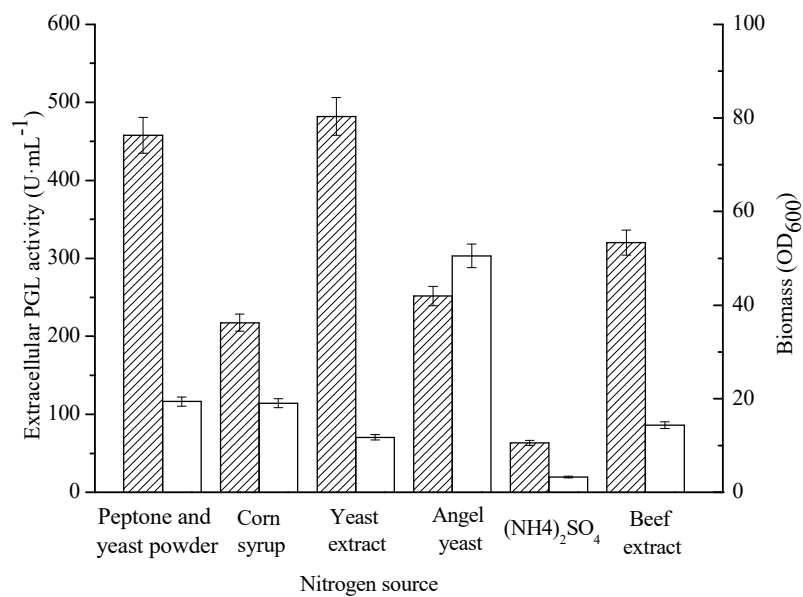

Fig. 3 Effect of different carbon source on cell growth and PGL production

Extracellular PGL activity (slash), Biomass (white).

As shown in fig. 3, the cell concentration after fermentation were $\left(\mathrm{OD}_{600}\right): 19.42,19.05,11.75,50.54$, 14.35 and 3.25 , and the extracell- ular enzyme activities were $\left(\mathrm{U} \cdot \mathrm{mL}^{-1}\right): 457.97,217.39,481.89,251.63,320.11$ and 63.41 respectively. The extracellular enzyme activity was highest when yeast extract was used as a nitrogen source for fermentation. When corn steep liquor, angel yeast, and beef extract were used as nitrogen sources, the extracellular PGL activity were low. Although angel yeast was suitable for bacterial growth, it could not promote enzyme production at the same time. Therefore, yeast extract was chosen as the nitrogen source for the fermentation medium of recombinant strains.

Then the optimum yeast extract concentration was explored. The medium concentration of yeast extract were $\left(\mathrm{g} \cdot \mathrm{L}^{-1}\right): 10,18,28,38$ and 48 , respectively. As shown in fig. 4 , the biomass were $\left(\mathrm{OD}_{600}\right): 17.98,19.05$, 20.11, 20.58 and 21.02. However, the extracell- ular enzyme activity were different. It increased $12.32 \%$ and $4.29 \%$ when the added amount of yeast extract increased from $10 \mathrm{~g} \cdot \mathrm{L}^{-1}$ to $18 \mathrm{~g} \cdot \mathrm{L}^{-1}$ and from $18 \mathrm{~g} \cdot \mathrm{L}^{-1}$ to $28 \mathrm{~g} \cdot \mathrm{L}^{-1}$, respectively. When the added amount of yeast extract increased from $28 \mathrm{~g} \cdot \mathrm{L}^{-1}$ to $38 \mathrm{~g} \cdot \mathrm{L}^{-1}$ and from $38 \mathrm{~g} \cdot \mathrm{L}^{-1}$ to $48 \mathrm{~g} \cdot \mathrm{L}^{-1}$, the extracellular enzyme activity were basically unchanged. Based on the raw material cost and other considerations, the added amount of yeast extract was set at $28 \mathrm{~g} \cdot \mathrm{L}^{-1}$.

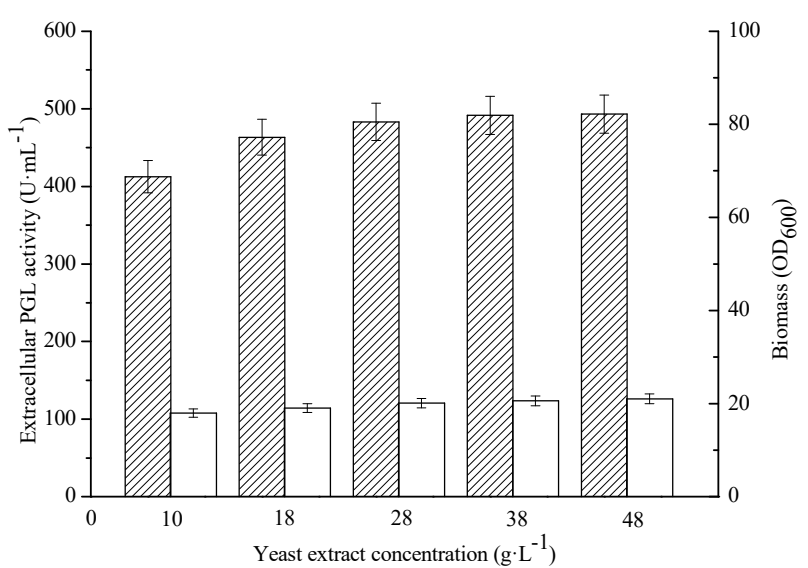

Fig.4 Effect of different yeast extract concentration on cell growth and PGL production

Extracellular PGL activity (slash), Biomass (white).

\subsection{The influence of inoculation amount on the growth and enzyme production of WB43CB}

Taking the original inoculation amount of $8 \%$ as the standard, the inoculation amount were adjusted to $4 \%$, $12 \%, 16 \%$ and $20 \%$.

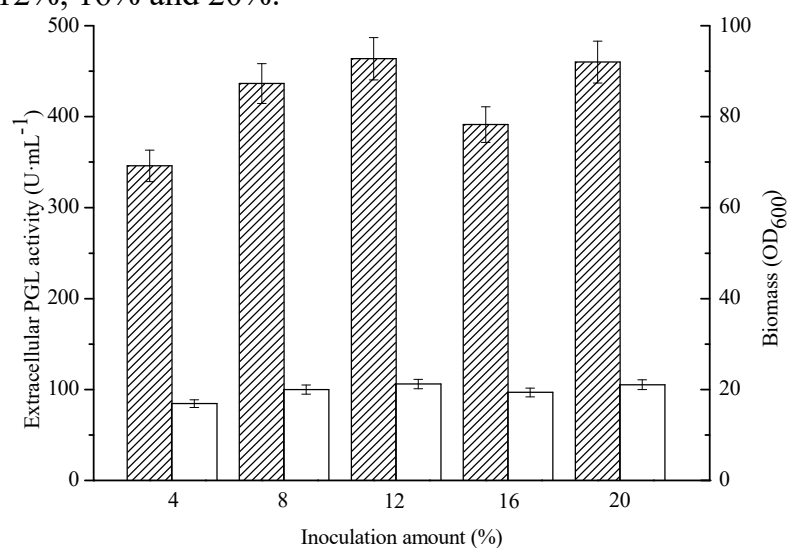

Fig. 5 Effect of different inoculum rate on cell growth and PGL production

Extracellular PGL activity (slash), Biomass (white)

As shown in fig. 5, when the inoculation amount were $4 \%, 8 \%, 12 \%, 16 \%$ and $20 \%$, the biomass were $\left(\mathrm{OD}_{600}\right): 16.9,19.99,21.2,19.35$ and 21.05 , and the extracellular PGL activity were $\left(\mathrm{U} \mathrm{mL}^{-1}\right): 346.02,436.60$, $463.77,391.31$ and 460.15 . The enzyme activity was the highest when the inoculation amount was $12 \%$. High inoculum will cause the rapid consumption of nutrients and reduce the enzyme production of the bacteria. Therefore, the inoculum amount when selecting the seed medium to transfer to the fermentation medium is $12 \%$.

\subsection{The influence of liquid volume on the growth and enzyme production of WB43CB}

Based on the $25 \mathrm{~mL} / 250 \mathrm{~mL}$ of original culture medium, the optimum liquid volume was explored, and the results were shown in fig. 6 . 


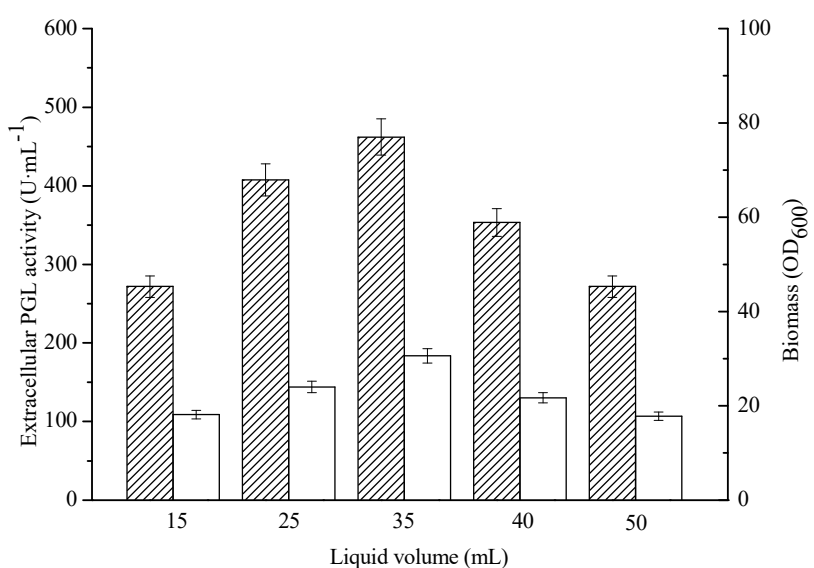

Fig. 6 Effect of different volume on cell growth and PGL prduction

Extracellular PGL activity (slash), Biomass (white)

When the filling volume is $15 \mathrm{~mL}, 25 \mathrm{~mL}, 35 \mathrm{~mL}, 40$ $\mathrm{mL}$, and $50 \mathrm{~mL}$, the biomass were $\left(\mathrm{OD}_{600}\right): 18.15,24.00$, $30.60,21.7,17.8$, and extracellular PGL activities were $\left(\mathrm{U} \cdot \mathrm{mL}^{-1}\right):$ 271.74, 407.61, 461.96, 353.26 and 271.74. Corresponding to the bacterial concentration, the extracellular enzyme activity is the highest when the filling volume is $35 \mathrm{~mL}$, reaching $461.96 \mathrm{U} \cdot \mathrm{mL}^{-1}$, higher than other filling volumes. When the liquid volume is high, the dissolved oxygen content in the culture medium may decrease, which will affect the growth and metabolism of the strains, and the enzyme production will decrease. Therefore, the optimal liquid volume for shake flask fermentation was $35 \mathrm{~mL} / 250 \mathrm{~mL}$.

\section{Conclusion}

By optimizing the fermentation medium, the final medium composition for PGL production by WB43CB was determined $\left(\mathrm{g} \mathrm{L}^{-1}\right)$ : Corn starch 25 , yeast extract 28 , $\mathrm{KH}_{2} \mathrm{PO}_{4} \quad 3, \mathrm{~K}_{2} \mathrm{HPO}_{4} \quad 9.2$, the fermentation was implemented at $37^{\circ} \mathrm{Cwith}$ the speed of $200 \mathrm{r} \cdot \mathrm{min}^{-1}$, inoculation volume of $12 \%, 250 \mathrm{~mL}$ shake flask with a volume of $35 \mathrm{~mL}$, the initial $\mathrm{pH}$ was 7.0. By optimizing the medium, the extracellular PGL activity of WB43CB was improved from $264.5 \mathrm{U} \cdot \mathrm{mL}^{-1}$ to $461.96 \mathrm{U} \cdot \mathrm{mL}^{-1}$, which laid a solid foundation for the expansion of PGL industrial production.

\section{Acknowledgments}

This work was financially supported by the Science and Technology Development Project of Tai'an (2017GX0057).

\section{References}

1. Fang S, Li J H, Liu L, Du G C, Chen J. Bioresour. Technol. 102, 10671-10678 (2011).

2. Li G, Rao L, Xue Y, Zhou C, Zhang Y, Ma Y H. Microbiol Biotechnol. 20, 670-677 (2010).

3. Pohl S, Harwood C.R. Adv. Appl. Microbiol. 73, 1-25 (2010).
4. Wang Z H, Wang Y, Zhang D.X, et al. Bioresour. Technol. 101, 1318-1323 (2010).

5. Zhang C, Yao J, Zhou C, et al. BMC. Biotechnol. 13, 26 (2013). 